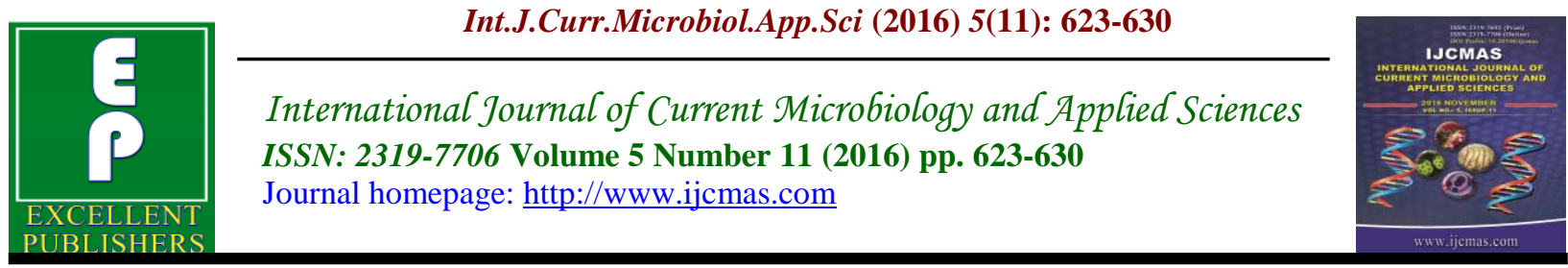

Original Research Article

http://dx.doi.org/10.20546/ijcmas.2016.511.073

\title{
Utilization of Low Cost Carbon Substrates and Optimization Studies for Maximum Yield of Polyhydroxybutyrate from B.megaterium
}

\author{
Neelam K. Naranje ${ }^{1 *}$, Bharat J. Wadher ${ }^{1}$ and Manohar G. Muddeshwar ${ }^{2}$ \\ ${ }^{1}$ P.G. Department of Microbiology, R.T.M. Nagpur University, Nagpur-440001, India \\ ${ }^{2}$ Department of Biochemistry, Government Medical College, Nagpur-440009, India \\ *Corresponding author
}

Keywords

B. megaterium,

Polyhydroxybutyrate,

Biodegradable

plastic, Optimization

carbon \& nitrogen

source.

\section{Article Info}

Accepted:

26 October 2016

Available Online:

10 November 2016

\section{A B S T R A C T}

Bacillus species are extremely widespread in nature and may be isolated from soil, water, dust, air and many foods. Being first described over 100 years ago B. megaterium has been an attractive choice for scientific as well as industrial applications. The study aimed at isolating a potential polyhydroxybutyrate (PHB) accumulating B. megaterium strain and optimization of process parameters for increased PHB production by the strain. Among different four substrates exploited for optimization study, Wheat bran and cotton seed oil cake found to be best for PHB accumulation. Use of ANOVA "one variable at a time" for optimization studies suggested the significant factors that influenced the PHB production by Bacillus megaterium.

\section{Introduction}

Use of plastics has become vital in our dayto-day life. These petrochemical plastics cannot be decomposed easily \& persist in the environment for many years thus contribute to the environment pollution. Hence biodegradable plastics have emerged as an alternative to overcome this problem. The history of biopolymers in bacterial cells goes back to Beijerinck in 1888 with the observation of the granules as refractile bodies in bacterial cells under the microscope. However, the Polyhydroxyalkanoates composition was established by Lemoigne in 1926 (Lemoigne, 1926).
Polyhydroxybutyrate (PHB) belongs to the family Polyhydroxyalkanoates, which is also known as Bioplastics. Several factors affect the production cost of $\mathrm{PHB}$, such as $\mathrm{PHB}$ productivity, content \& yield and the cost of the carbon substrate. One possible strategy for reducing costs is to utilize the alternative substrates such as natural products, industrial wastes and agro industrial residues for PHB production by different fermentation process(Castilho, Mitchell, \& Freire, 2009; Pandian et al., 2010). Solidstate fermentation (SSF) is defined as any fermentation process performed on a nonsoluble material that acts as physical support 
and source of nutrients (sometimes only as physical support) in the absence or nearabsence of free flowing liquid.

Nowadays different agro industrial residues like soy molasses, sugarcane molasses, sesame oil cake, groundnut oil cake, corn steep liquor etc., have been reported for PHB production.(Full, Jung, \& Madigan, 2006; Gouda, Swellam, \& Omar, 2001; Ramadas, Singh, Soccol, \& Pandey, 2009; Van-Thuoc, Quillaguaman, Mamo, \& Mattiasson, 2008) However, to the best of our knowledge the production process and optimization using agro wastes viz. Wheat bran, Chickpeas chaff, Pigeon peas chaff and Cotton seed oil cake with B.megaterium in solid state cultivation has not been reported yet for the production of PHB. Therefore in this study we have selected these agro-wastes as substrates.

\section{Materials and Methods}

Microorganism and maintenance: Bacillus megaterium isolated from different soil samples on Hichorme Bacillus Agar (Himedia). Culture was maintained on nutrient agar (Himedia) slant at $4^{\circ} \mathrm{C}$. The slants were sub-cultured once a month.

Inoculum: Bacillus megaterium inoculum was prepared by transferring growth of the fresh slant into $50 \mathrm{ml} \mathrm{LB}$ broth. The inoculated flask was incubated at $37^{\circ} \mathrm{C}$ at $120 \mathrm{rpm}$ for $12-18 \mathrm{~h}$ and $5 \mathrm{ml}$ of this pregrown culture used to inoculate production medium.

PHB production using agro waste: Experiments were setup in shake flasks for production of the biopolymer as described by Sathiyanarayan et al., (Sathiyanarayanan, Kiran, Selvin, and Saibaba, 2013).The four agro wastes as substrates selected for the study are: Wheat bran, Chick peas chaff,
Pigeon peas Chaff and Cotton seed oil cake (COC). All the substrates were washed with distilled water, autoclaved \& dried in a hot air oven at $60^{\circ} \mathrm{C} \&$ grinded into fine powder. These sterilized powdered substrates were added as the sole carbon source and the media was supplemented with minimal salts trace element.

SSC (Solid State Culture) media was developed for the optimization of PHA production. The production of $\mathrm{PHB}$ was performed duplicate in $250 \mathrm{ml}$ Erlenmeyer flasks.

To develop the SSC, $10 \mathrm{~g}$ dried substrate mixed with $5 \mathrm{ml}$ of trace element solution (moistening media) and $10 \mathrm{ml}$ of sterile distilled water. The trace element solution which contain in $\mathrm{mg} / \mathrm{ml}$ of distilled water viz.: $\mathrm{Na}_{2} \mathrm{SO}_{4}, 25 \mathrm{mg} ; \mathrm{FeSO}_{4} \cdot 7 \mathrm{H}_{2} \mathrm{O}, 25 \mathrm{mg}$, $\mathrm{MnSO}_{4} \cdot 4 \mathrm{H}_{2} \mathrm{O}, 4.06 \mathrm{mg} ; \mathrm{ZnSO}_{4} \cdot 7 \mathrm{H}_{2} \mathrm{O}, 4.40$ $\mathrm{mg} ; \mathrm{CuSO}_{4} \cdot 5 \mathrm{H}_{2} \mathrm{O}, 0.79 \mathrm{mg} ; \mathrm{CaCl}_{2} \cdot 2 \mathrm{H}_{2} \mathrm{O}$, $73.4 \mathrm{mg}$; $\mathrm{pH}$ 7.0. The contents were double sterilized by autoclaving at $15 \mathrm{lb}$ for $20 \mathrm{~min}$ and the sterilized solid substrates were inoculated with $5 \mathrm{ml}$ of bacterial culture as inoculum for one gram of substrate, mixed properly and incubated at $30^{\circ} \mathrm{C}$ on a rotatory shaker at $120 \mathrm{rpm}$ for $24 \mathrm{hrs}$.

PHB extraction \& Quantification: PHB extraction was done by using the dispersion method of sodium hypochlorite and chloroform (Law and Slepecky, 1961) (Law $\&$ Slepecky, 1961). For the extraction of polymer, $30 \mathrm{~mL}$ distilled water was added to fermented substrate and stirred for $20 \mathrm{~min}$, filtered through whatmann paper and remaining residues washed with $10 \mathrm{~mL}$ of sterile distilled water and filtered. The combined filtrates were centrifuged for 10 min at $8000 \mathrm{rpm}$ and washed with distilled water twice (Sathiyanarayanan et al., 2013). The final bacterial pellet was used for PHB extraction \& quantification using 
Chloroform extraction method.(Hahn, Chang, Kim, \& Chang, 1994; Kunioka, Nakamura, \& Doi, 1988; Law \& Slepecky, 1961; Williamson \& Wilkinson, 1958) Cell pellet was lysed by Sodium hypochloride at $37^{\circ} \mathrm{C}$ for $1 \mathrm{hr}$. Obtained cell pellet was then washed with water, acetone and alcohol sequentially.. The remaining lipid granules were transferred into boiling chloroform for 10 min (in hot water bath), which extract PHB and dissolves any residual contaminants. This extraction is repeated twice and the pooled extracts made up with chloroform to $10 \mathrm{ml}$. The settled material after evaporation of chloroform was dried at $40^{\circ} \mathrm{C}$ for $30 \mathrm{~min}$. The white powder was dissolved in concentrated $\mathrm{H}_{2} \mathrm{SO}_{4}(10 \mathrm{~mL})$ and heated for $10 \mathrm{~min}$ at $100^{\circ} \mathrm{C}$. PHB crystals are now converted to crotonic acid. After cooling the sample was transferred to $1 \mathrm{~cm}$ quartz cuvette and absorbance was measured at $235 \mathrm{~nm}$ against with crotonic acid standard curve by using sulfuric acid as blank in uv spectrophotometer (Norris \& Ribbons, 1971; White, 2010).

\section{Optimization of physico-chemical parameters for PHB production using one-factor-at-a-time experiments}

Evaluation of Upstream Process parameters influencing the PHB accumulation was studied by search one factor at a time method.(Sathiyanarayanan et al., 2013) To determine optimum conditions (like $\mathrm{pH}$, temperature, inoculums age, Ammonium chloride concentration) experiments were set up as described in above varying only one parameter at a time in each experiment.

Statistical Analysis: Statistical analysis (means) of the experimental data was carried out by Data analysis ANOVA in Microsoft excel 2007. ANOVA (one variable at a time) was performed for each of the optimization factors affecting the production of PHB by
Bacillus megaterium. The P-values obtained from optimization studies were used to confirm the significant factors that influenced the PHB production by Bacillus megaterium.

\section{Results and Discussion}

Several cultural parameters were evaluated to determine their effect on PHB production in SSF fermentation. P-value was found to be significant for all the factors $(\mathrm{P} \leq 0.05$ level of significance) except Incubation temperature \& $\mathrm{NH} 4 \mathrm{Cl}$ concentration indicating the significant influence of all the upstream parameters tested.

\section{Evaluation of agro-industrial residues as the carbon substrate}

The use of readily available cheap agroindustrial residues carbon sources may reduce the higher production cost. B.megaterium accumulated a significant amount of PHB from a variety of carbon sources. Among four agro waste substrates, max PHB accumulation found in wheat bran $(1.02 \mathrm{mg} / \mathrm{ml})$ \& nearly similar value found from cotton seed oil cake $(0.86 \mathrm{mg} / \mathrm{ml})$ also. Low yield of PHB found with Chickpeas chaff $(0.53 \mathrm{mg} / \mathrm{ml})$ \& pigeon peas chaff $(0.44 \mathrm{mg} / \mathrm{ml})$. Therefore only two substrates wheat bran \& COC were selected for further optimization study. (Graph 1)

\section{Effect of incubation temperature on PHB production}

Effect of incubation temperature on PHB accumulation was studied over a range of temperature $25^{\circ} \mathrm{C}$ to $40^{\circ} \mathrm{C}$. The data obtained from the effect of incubation temperature indicated the range of $30-37^{\circ} \mathrm{C}$ was suitable for the PHB production (Graph 2). $30^{\circ} \mathrm{C}$ was found to be suitable \& optimum temperature for PHB production. Low PHB production 
noted at $25^{\circ} \mathrm{C}$ and $40^{\circ} \mathrm{C}$. Similar results also reported by Sathiyanarayan et al., (Sathiyanarayanan et al., 2013).

No significant difference $(\mathrm{F}=3.07, \mathrm{P}=0.19)$ was observed between the means of yield of PHB with respect to Incubation temperature. The highest \& lowest yield of PHB 1.46 $\mathrm{mg} / \mathrm{ml} \& 0.27 \mathrm{mg} / \mathrm{ml}$ observed in $30^{\circ} \mathrm{C} \&$ $40^{\circ} \mathrm{C}$ incubation temperature respectively.

Effect of initial mediums pH on PHB production: It has been reported that initial medium $\mathrm{pH}$ significantly influence the PHB production by changing the bioavailability of some of the trace elements (Grothe, MooYoung, \& Chisti, 1999). Effect of initial $\mathrm{pH}$ studies showed that as the $\mathrm{pH}$ in the medium increases, PHB production increased up to $\mathrm{pH}$ 7.5. Bacillus showed maximum PHB production $(\mathrm{mg} / \mathrm{ml})$ at $\mathrm{pH} 7.5$, and at alkaline $\mathrm{pH}$ there was a sharp decrease in PHB production (Graph 3). These findings are comparable to results of Sathiyanarayan et. al (Sathiyanarayanan et al., 2013). It has been reported that $\mathrm{pH}$ in the range of $6.0-$ 7.5 was the best for microbial growth, and the maximum growth and PHB production of Alcaligenes eutrophus was reported at optimum $\mathrm{pH}$ of 6.9 (PALLERONI \& PALLERONI, 1978) . A significant difference $(\mathrm{F}=8.6, \mathrm{P}=0.01)$ was observed between the means of yield of PHB with respect to $\mathrm{pH}$. The highest \& lowest yield of PHB $1.73 \mathrm{mg} / \mathrm{ml} \& 0.15 \mathrm{mg} / \mathrm{ml}$ observed in $7.5 \& 8.5 \mathrm{pH}$ respectively.

Effect of inoculum age on PHB production: The effect of inoculum age on PHB production by Bacillus was studied by inoculating the production medium using 12 $-24 \mathrm{~h}$ aged inoculum. It is reported that inoculum age affected both the growth rate and PHB accumulation (Kareem et al.).

The data represented in (Graph 4) indicated that the inoculum age of $18 \mathrm{~h}$ gave maximum PHB production. After $18 \mathrm{~h}$ there was an inverse relation for inoculum age and PHB production, since the specific growth rate of older inoculum age was lower and it took longer for the culture to reach stationary phase (Asenjo \& Suk, 1986). When these bacterial cells were transferred from actively growing phase to the production medium, the easily assimable carbon source in the medium could facilitated the synthesis of PHB. A significant difference $(\mathrm{F}=9.48, \mathrm{P}=0.01)$ was observed between the means of yield of PHB with respect to inoculums age. The highest \& lowest yield of PHB $2.57 \mathrm{mg} / \mathrm{ml}$ $\& 0.03 \mathrm{mg} / \mathrm{ml}$ observed in $18 \mathrm{hrs} \& 6 \mathrm{hrs}$ old culture respectively.

Graph.1 Effect of agro-industrial residues as the carbon substrate on PHB production by B.megaterium

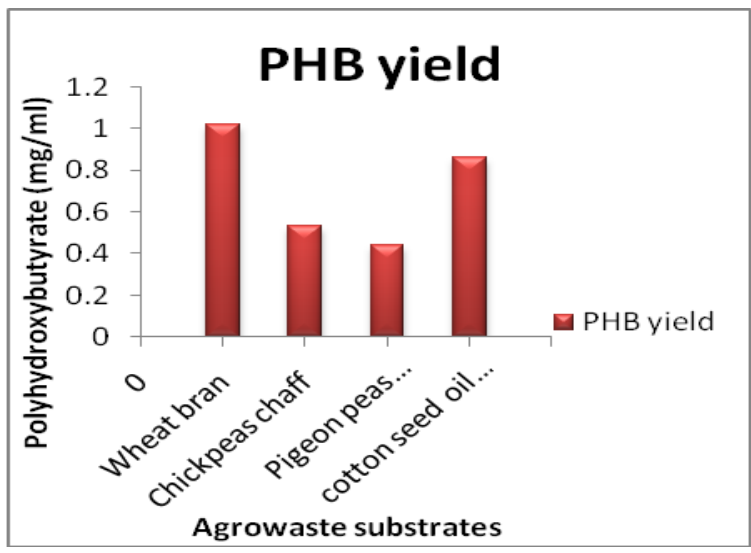


Graph.2 Effect of Incubation temperature on PHB production by B.megaterium.

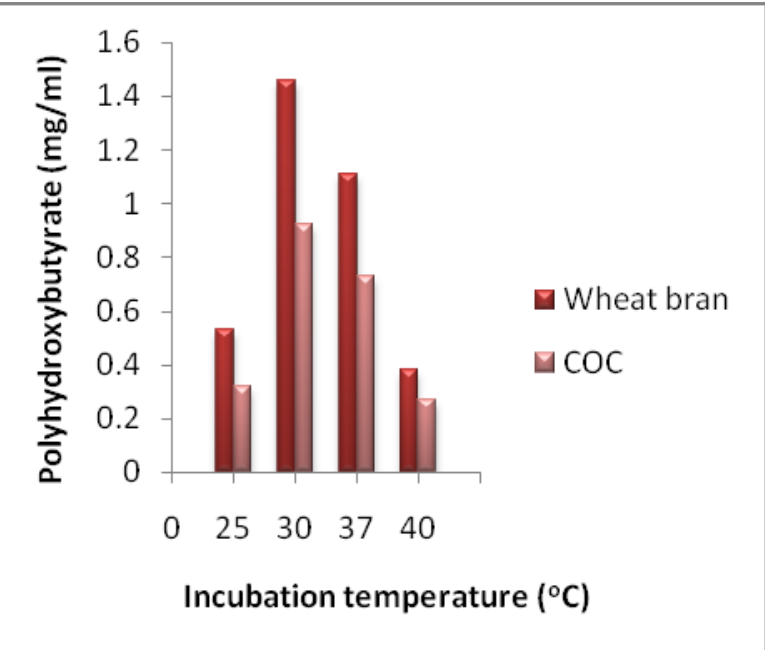

Graph.3 Effect of Initial pH of medium on PHB production by B.megaterium.

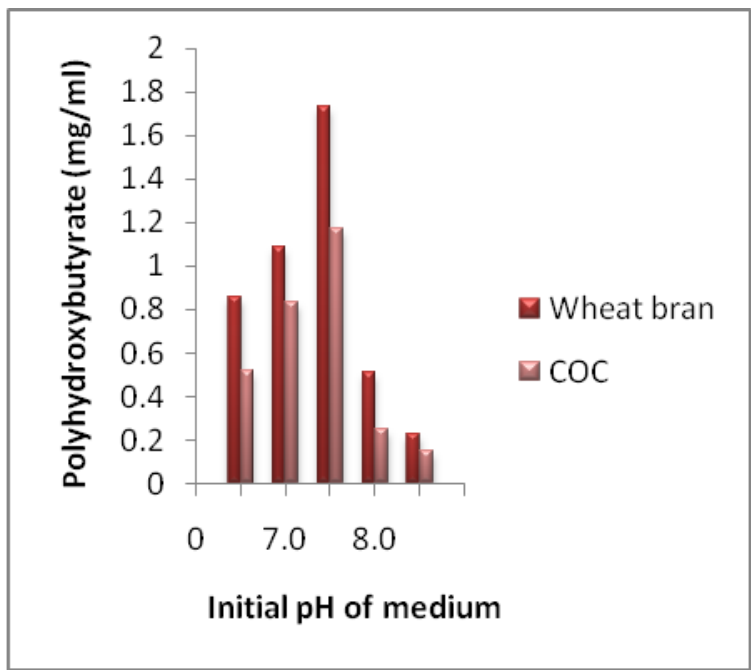

Graph.4 Effect of Inoculum age on PHB production by B.megaterium.

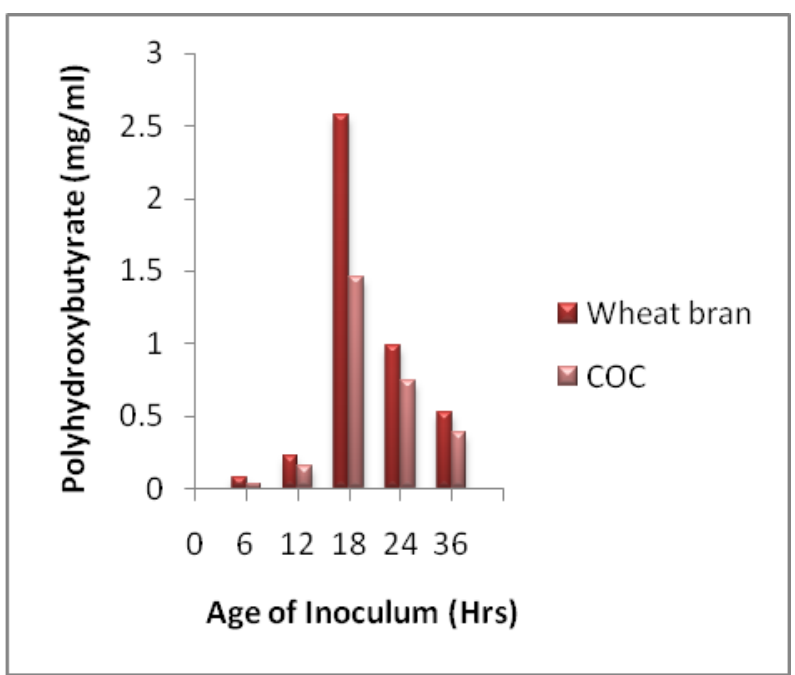


Graph.5 Effect of Ammonium Chloride concenration on PHB production by B.megaterium.

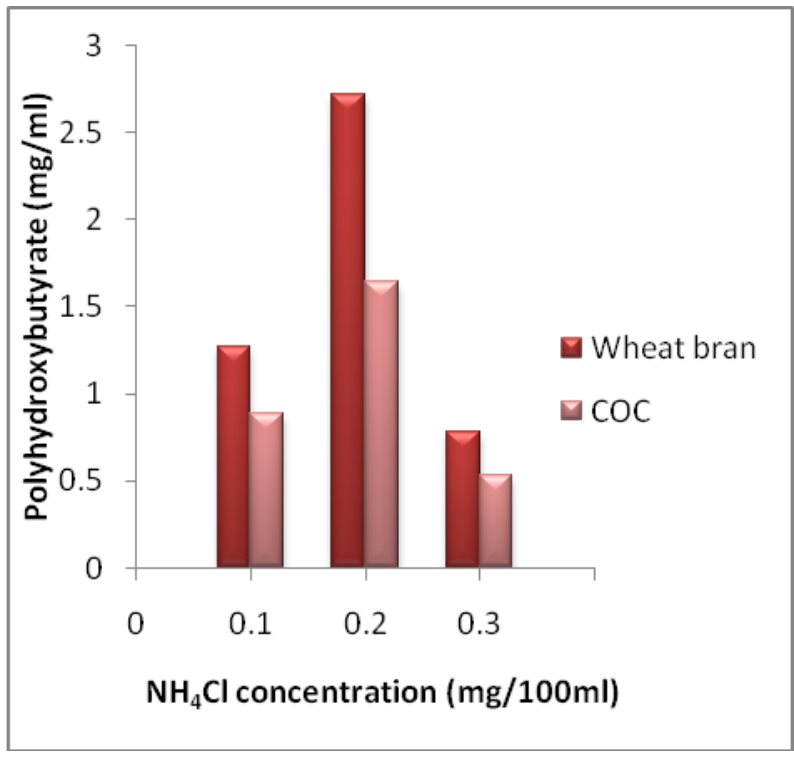

Effect of inorganic nitrogen source on PHB production: In the case of inorganic nitrogen sources, ammonium chloride (Filter sterilze) gave PHB yield $2.72 \mathrm{mg} / \mathrm{ml}$, which was comparable to the result, obtained with Bacillus megaterium (Vijayendra et al., 2007). Studies were carried out to evaluate the effect of nitrogen sources on PHB production by using inorganic nitrogen sources $0.1,0.2, \quad 0.3 \mathrm{mg} / 100 \mathrm{ml}$ in the medium.

Higher yields of the polymer were observed when nitrogen source in the form of ammonium chloride was limited at 0.2 $\mathrm{mg} / 100 \mathrm{ml}$. In complete absence ammonium chloride, PHB yield was comparatively low. (Graph 5)This indicates although PHB synthesis is enhanced under nutrient limiting conditions but certain strains may not be able to produce high amount of PHB at very low nitrogen concentrations. The result indicated $\mathrm{NH}_{4} \mathrm{Cl}$ as one of the promising nitrogen source for PHB production by B.megaterium.

No significant difference $(\mathrm{F}=5.4, \mathrm{P}=0.1)$ was observed between the means of yield of
PHB with respect to ammonium chloride concentration. The highest \& lowest yield of PHB $2.72 \mathrm{mg} / \mathrm{ml} \mathrm{\&} 0.53 \mathrm{mg} / \mathrm{ml}$ observed in $0.2 \quad \& \quad 0.3 \quad \mathrm{mg} / 100 \mathrm{ml}$ concentration respectively.

In conclusion, an imbalance of essential nutrients is the major factor that influences bacterial accumulation of intracellular PHB. Type of limiting nutrient involved may differ from one genus to other genus of bacteria. Several Bacillus spp are known to produce PHB under varied growth conditions and they are found capable of producing various PHB from structurally unrelated carbon sources(Chen, König, \& Lafferty, 1991; Valappil, Boccaccini, Bucke, \& Roy, 2007). In the present study media optimization studies were carried out using different carbon sources \& various physicochemical parameters.

The results of the present investigation suggest that various process parameters like substrate concentration, nitrogen source and physical parameters were significantly influenced the PHB production. Considering the results obtained in the current study, we 
can also conclude that the strain used in this study offers great potential for further investigation on PHB production under solid state culture.

\section{References}

Asenjo, J.A., \& Suk, J.S. 1986. Microbial conversion of methane into poly- $\beta$ hydroxybutyrate (PHB): growth and intracellular product accumulation in a type II methanotroph. J. Fermentation Technol., 64(4): 271-278.

Castilho, L.R., Mitchell, D.A., \& Freire, D. M. 2009. Production of polyhydroxyalkanoates (PHAs) from waste materials and by-products by submerged and solid-state fermentation. Biores. Technol., 100(23), 5996-6009.

Chen, G.Q., König, K.H., \& Lafferty, R.M. 1991. Occurrence of poly-d (-)-3hydroxyalkanoates in the genus Bacillus. FEMS Microbiol. Lett., 84(2), 173-176.

Full, T., Jung, D., \& Madigan, M. 2006. Production of poly- $\beta$ hydroxyalkanoates from soy molasses oligosaccharides by new, rapidly growing Bacillus species. Lett. Appl. Microbiol., 43(4), 377-384.

Gouda, M.K., Swellam, A.E., \& Omar, S.H. 2001. Production of PHB by a Bacillus megaterium strain using sugarcane molasses and corn steep liquor as sole carbon and nitrogen sources. Microbiol. Res., 156(3): 201207.

Grothe, E., Moo-Young, M., \& Chisti, Y. 1999. Fermentation optimization for the production of poly $(\beta$ hydroxybutyric acid) microbial thermoplastic. Enzyme and Microbial Technol., 25(1), 132-141.

Hahn, S.K., Chang, Y.K., Kim, B.S., \& Chang, H.N. 1994. Optimization of microbial poly (3- hydroxybutyrate) recover using dispersions of sodium hypochlorite solution and chloroform. Biotechnol. Bioengi., 44(2), 256-261.

Kareem, H.A., Khalaf, M., Gebreel, H., ElMahalawy, A., Omar, S., \& Hamed, D. Radiation Microbiology Dept.,(NCRRT), AEA. PO Box 29 Nasr City, Cairo, Egypt* Microbiology Department, Faculty of Science, Ain Shams University.** Botany Department, Faculty of Science, Alexandria University.

Kunioka, M., Nakamura, Y., \& Doi, Y. 1988. New bacterial copolyesters produced in Alcaligenes entrophus from organic acids. Polymer communications, 29(6), 174-176.

Law, J. H., \& Slepecky, R. A. (1961). Assay of poly- $\beta$-hydroxybutyric acid. $J$. bacteriol., 82(1), 33-36.

Lemoigne, M. 1926. Produit de déshydratation et de polymérisation de l'acide $\beta$-oxybutyrique. Bull. Soc. Chim. Biol., 8, 770-782.

Norris, J.R., \& Ribbons, D.W. 1971. Methods in Microbiol., (Vol. 5): Academic Press.

Palleroni, N.J., Palleroni, A.V. 1978. Alcaligenes latus, a new species of hydrogen-utilizing bacteria. Int. J. Systematic and Evol. Microbiol., 28(3), 416-424.

Pandian, S.R., Deepak, V., Kalishwaralal, K., Rameshkumar, N., Jeyaraj, M., \& Gurunathan, S. 2010. Optimization and fed-batch production of PHB utilizing dairy waste and sea water as nutrient sources by Bacillus megaterium SRKP-3. Biores. Technol., 101(2), 705-711.

Ramadas, N.V., Singh, S.K., Soccol, C.R., \& Pandey, A. 2009. Polyhydroxybutyrate production using agro-industrial residue as substrate by Bacillus sphaericus NCIM 5149. 
Brazilian archives of Biol. Technol., 52(1), 17-23.

Sathiyanarayanan, G., Kiran, G. S., Selvin, J., \& Saibaba, G. 2013. Optimization of polyhydroxybutyrate production by marine Bacillus megaterium MSBN04 under solid state culture. Int. J. Biol. Macromol., 60, 253-261.

Valappil, S.P., Boccaccini, A.R., Bucke, C., $\begin{array}{llll}\& & \text { Roy, } & \text { I. } & 2007 .\end{array}$ Polyhydroxyalkanoates in Grampositive bacteria: insights from the genera Bacillus and Streptomyces. Antonie Van Leeuwenhoek, 91(1), 117.

Van Thuoc, D., Quillaguaman, J., Mamo, G., \& Mattiasson, B. 2008. Utilization of agricultural residues for poly (3 hydroxybutyrate) production by Halomonas boliviensis LC1. J. Appl. Microbiol., 104(2), 420-428.

Vijayendra, S., Rastogi, N., Shamala, T., Kumar, P. A., Kshama, L., \& Joshi, G. 2007. Optimization of polyhydroxybutyrate production by Bacillus sp. CFR 256 with corn steep liquor as a nitrogen source. Indian $J$. Microbiol., 47(2), 170-175.

White, P. 2010. Data-handling in Biomedical science: Cambridge University Press.

Williamson, D., \& Wilkinson, J. 1958. The isolation and estimation of the poly- $\beta$ hydroxy-butyrate inclusions of Bacillus species. Microbiol., 19(1), 198-209.

\section{How to cite this article:}

Neelam K. Naranje, Bharat J. Wadher and Manohar G. Muddeshwar. 2016. Utilization of Low Cost Carbon Substrates and Optimization Studies for Maximum Yield of Polyhydroxybutyrate from B.megaterium. Int.J.Curr.Microbiol.App.Sci. 5(11): 623-630. doi: http://dx.doi.org/10.20546/ijcmas.2016.511.073 